Vol. 10, N. 2, Year 2017

ISSN: 2037-0830 - DOI: 10.1515/rem-2017-0010

\title{
Robotics for soft skills training
}

\author{
Franco Rubinacci, ${ }^{a}$ Michela Ponticorvo, ${ }^{\mathrm{b}}$ Rosa Passariello, ${ }^{\mathrm{c}}$ Orazio Miglino ${ }^{\mathrm{d}}$ \\ ${ }^{a}$ University of Naples 'Federico II', Naples, Italy, franco.rubinacci@unina.it \\ ${ }^{b}$ University of Naples 'Federico II', Naples, Italy, michela.ponticorvo@unina.it, ORCID 0000-0003-2451- \\ 9539 \\ ${ }^{c}$ University of Naples 'Federico II', Naples, Italy \\ ${ }^{d}$ University of Naples 'Federico II', Naples, Italy, orazio.miglino@unina.it
}

\begin{abstract}
Robotics is a powerful tool in education and it has gained a notable impact in the field of teaching computer science, engineering, math, physics and similar. As educational robotics laboratories stimulate many different abilities in students, such as problem solving and group working, it is possible to use robotics to promote soft skills as well.

Soft skills are necessary to complement hard skills to build the 21st century professionalism, so it seems relevant to start promoting these skills as soon as possible. In this paper, we describe a lab for primary and first grade secondary schools in which robotics is employed to train soft skills in an informal context.
\end{abstract}

Keywords: primary school; laboratory

\section{Introduction}

Robotics is a powerful tool to educate, and in recent years, it has gained a primary role in informal and formal education contexts. Many researches have been devoted to this issue and new practices have been proposed to exploit educational robotics potentialities, especially in STEM education (Merdan et al., 2016).

From an interesting review on this theme (Benitti, 2012), which analysed ten relevant articles extracted from bibliographic databases, it emerges that the content to be taught employing robotics is mostly related to the fields of physics and mathematics $(80 \%)$, but it is worth noting that these experiences report teaching distances, angles, kinematics, graphs, fractions, and geospatial concepts together with problem solving, logic and scientific methodology - skills that can be promoted through robotics.

Moreover, some studies apply robotics to teaching the basic principles of evolution (Whittier and Robinson, 2007; Author et al., 1999; Author et al., 2004; Author et al., 2007), developing social communication skills (Owens et al., 2008) and learning to manage complex systems (Author et al., 2008; Author et al., 2016).

In the last few years, Educational Robotics has indeed experienced a new explosion for the training of STEM that are crucial for competitiveness, but, for the goal of our work, it is useful to highlight that, together with this main vein, some steps have been taken in the direction of using robotics to promote other skills, such as communication.

Communication, problem solving, and system management belong to soft skills, a concept widely used in training and vocational context, which refers to the personal skills in opposition with the hard, technical skills (Bacolod et al., 2009; Caudron, 1999). It is indeed a multiform concept that includes different dimensions of the personal sphere on emotional, behavioural, and cognitive side.

In the last years, it has become evident that these skills are important in almost every context: for students along their career, for working people at every level, for professionals which interact with other people and so on. 
For their crucial role in the business field, many expensive and time-demanding programs are proposed, but it is also possible to impart training on soft skills with less conventional methods, such as serious games (Dell'Aquila et al., 2017) and the training can start much before the work world entrance.

We believe that educational robotics can open itself to the challenging field of soft-skills, especially in the case of children and adolescents. For this reason, in this paper, we describe an experience in which robotics has been employed to promote soft skills in primary and first level secondary school children very precociously as compared to the other program that are mainly addressed to workers or university students. In the following sections, we will describe this educational robotics example in detail.

\section{The robotic lab for Soft Skills training with children}

In this section, we describe a successful laboratory experience that was held in Naples, at Città della Scienza. This is a cultural initiative to promote and popularize scientific knowledge. Città della Scienza has a multifunctional structure with an interactive scientific museum and a training centre. In this training centre, many initiatives allow children to take part in the laboratories in an informal context. The Soft Skills lab employed the well-known Lego Mindstorms kit.

This lab started from the hypothesis that Educational Robotics could be effectively applied to soft-skills training and the first step was to investigate the teachers' and students' expectations about this issue, as a useful premise to the consequent research.

\subsection{Lab scheduling}

The Soft Skills lab was arranged as follows: first, a pre-lab questionnaire was administered both to teachers and students to assess their expectations about the laboratory, mainly about hard skills and soft skills.

Then the lab conductor introduced the robotic kit, educational robotics goals and the task to be accomplished.

After this general introduction, the group, usually a classroom of about 20 students, is divided into 4 sub-groups and start building their robot. Some parts are pre-assembled to facilitate the task in a reduced amount of time. When the building phase is over, the groups must conceive and implement the code to accomplish the task which can be pathfollowing, navigation task, or a competition between groups. The groups can try their solution once and then fix any problem in the code.

At the end the feedback is delivered by the lab conductor and the post-lab questionnaire is administered. The whole procedure lasts 75 minutes.

\subsection{Participants and robot}

The Soft Skills lab lasted from February 2016 to May 2016 and involved students accompanied by teachers: it was attended by 278 children, who were either studying in the last year of primary school or the second year of first level secondary school. The average age of the participating students was 11.65 years. The classrooms were accompanied with 42 teachers.

The robot was built using the LEGO Mindstorms kit, which is widely used in education (Klassner and Anderson, 2003). The basic LEGO Mindstorms kit contains 750 building block pieces and the programmable control unit, the RCX. It includes sensors for touch, light, angle (rotation), and temperature and actuator motor and light.

In this lab, the students used the tool for programming the RCX provided by LEGO. It is a development environment with an interface that models programming as a process of dragging puzzle pieces together to build a chain. The pieces are the program steps whereas the chain is the complete program. It is possible to use the basic programming concepts such as loops and subroutines. The robot morphology that was used in Soft Skills lab is depicted in Figure 1. 


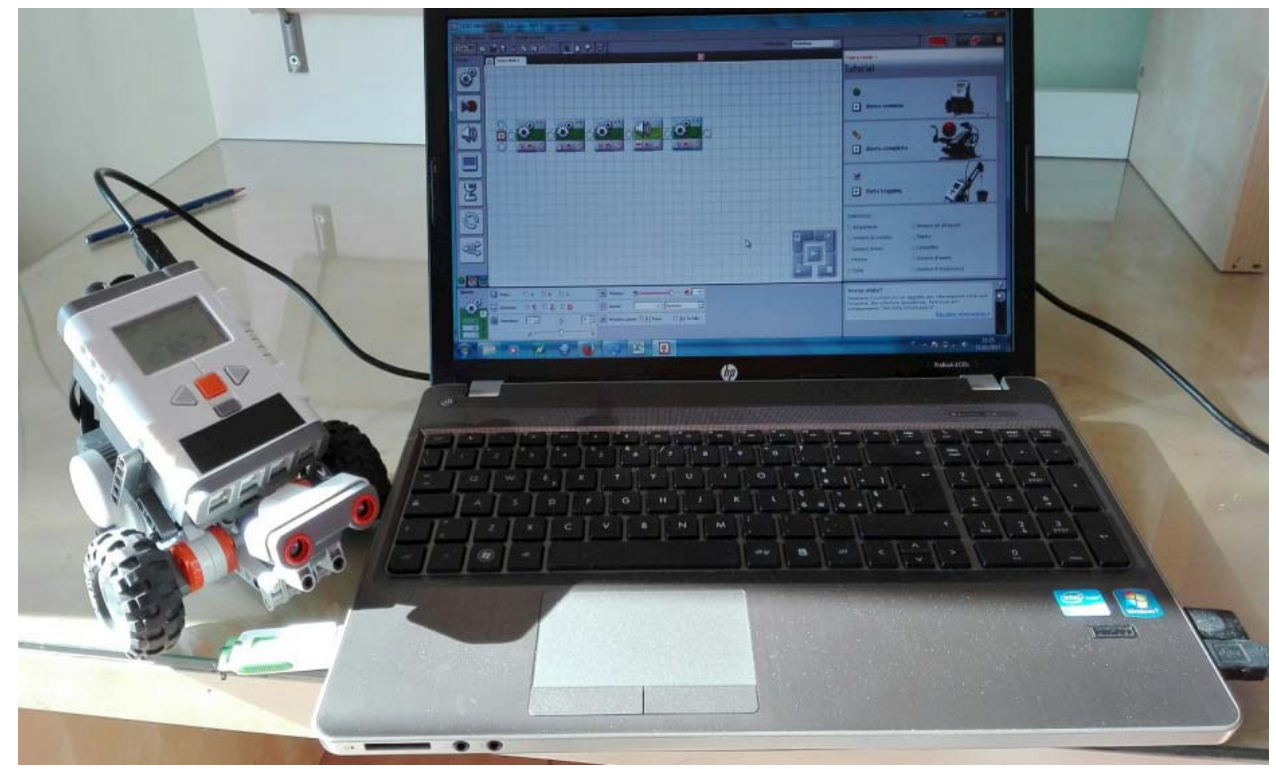

Fig. 1 The robot morphology used for the Soft Skills Lab together with a screenshot from the Lego software

\subsection{Questionnaires}

Four questionnaires were used for data collection, 2 questionnaires for students and 2 questionnaires for teachers. They were administered before (pre-test) and after (post-test) the lab experience in the same room where the lab took place. It was compiled individually and in an anonymous manner. The researchers indicated a code to match the preand post-lab questionnaires for each participant.

The participants could reply to the questionnaires items using a 5-point Likert scale, where 1 indicated complete disagreement and 5 indicated complete agreement with the proposed sentence.

The questionnaire for students investigated their expectations (pre-lab) and their opinion (post-lab) about the lab's efficacy to stimulate their interest in science, robotics, technology, maths, coding, robot construction, robot programming, team work, and problem solving.

The questionnaire for teachers investigated their expectation (pre-lab) and opinion (post-lab) about the lab's efficacy to stimulate students' interest in the same fields.

\section{Results}

In this section, some data about the Soft Skills lab experience at Città della Scienza are reported. Students evaluated the laboratory very positively on the technical skills promotion.

Regarding soft skills enhancing, it emerges that students have high expectations about team work, problem understanding, and problem solving. 
Robotics for soft skills training

Rubinacci, Pontecorvo, Passariello, Miglino

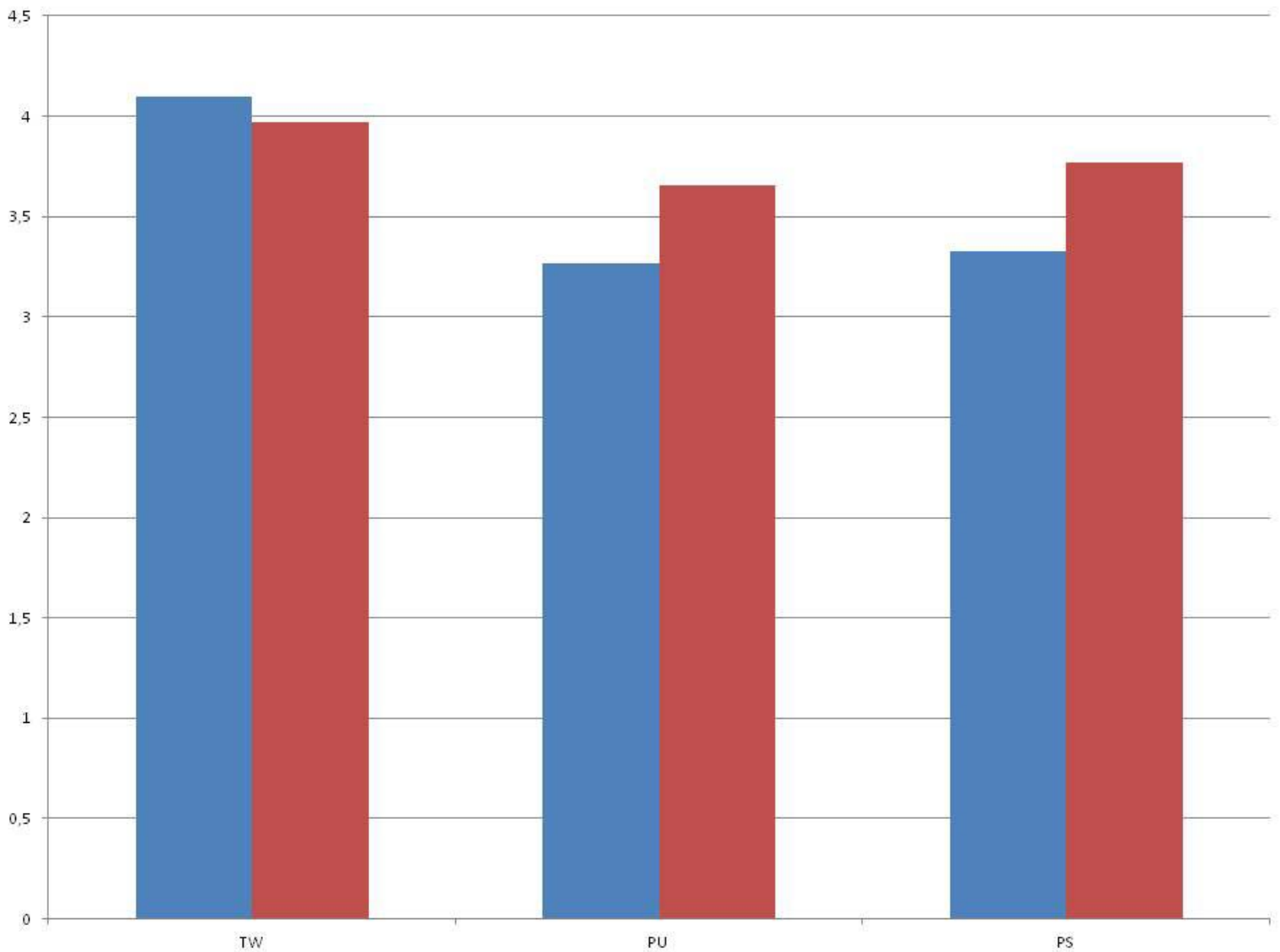

Fig. 2 The graph represents the average for the item regarding the soft skills for the students. The data for pre-lab questionnaire is represented by the blue bar and the data for post-lab questionnaire is represented by the red bar. TW stands for team work, PU for problem understanding and PS for problem solving.

In the case of problem understanding and problem solving, the students' opinion is better than expectations whereas the opposite happens for team work. The Pearson correlation values between the pre-lab and post-lab questionnaires are reported in Table 1 .

Table 1. Correlation between pre-lab and post-lab for students. Data in italics indicate values with probability under 0.05

\begin{tabular}{llll}
\hline & TW pre & PU pre & PS pre \\
\hline TW post & 0.429 & 0.162 & 0.121 \\
PU post & 0.096 & 0.428 & 0.359 \\
PS post & 0.111 & 0.409 & 0.381 \\
\hline
\end{tabular}

Regarding the teachers, the lab experience improved their consideration of lab effectiveness for promoting soft skills. 


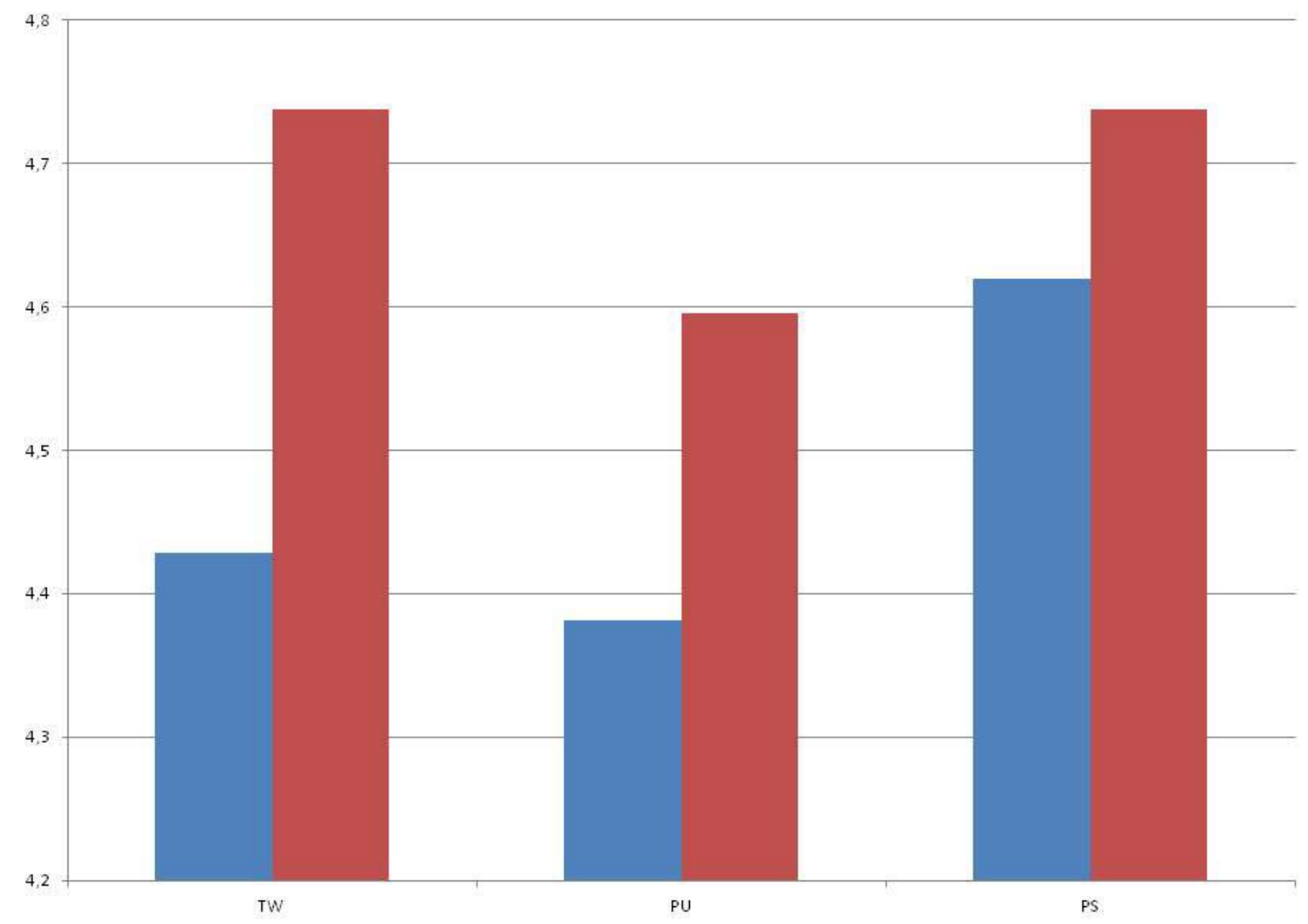

Fig. 3 The graph represents the average for the item regarding soft skills for teachers. The data for pre-lab questionnaire is represented by the blue bar and the data for post-lab questionnaire is represented by the red bar. TW stands for team work, PU for problem understanding and PS for problem solving.

Also, for the teachers, the Pearson correlation was calculated for the soft skills parameters. The data are reported in table 2 .

Table 1. Correlation between pre-lab and post-lab for teachers. Data in italics indicate values with probability under 0.05

\begin{tabular}{llll}
\hline & TW pre & PU pre & PS pre \\
\hline TW post & 0.350 & 0.154 & 0.300 \\
PU post & 0.500 & 0.250 & 0.345 \\
PS post & 0.534 & 0.225 & 0.301 \\
\hline
\end{tabular}

\section{Conclusions}

Data indicates that the students and teachers were confident about the lab effectiveness in promoting soft skills. Also, the teachers agreed that it was a good chance to stimulate collaboration, group working and enhanced communication abilities in students.

The feedback from the teachers has confirmed that it stimulated students interest in STEM and coding as well as their skills in group work, mediation and negotiation, problem definition and solving.

Also, the students evaluated the lab very positively, both about hard skills and soft skills.

This lab allowed the students to start acquiring very precociously the knowledge that transforms into skills and competencies, which is crucial for their future in academic and working careers. Even though this experience can be considered as just the first step in the lengthy process to widen the application of robotics to non-technical skills acquisition, there is no doubt that there is a promising premise for the effectiveness of this challenging issue. 
In fact, the users' perception of robotics as a tool to promote soft skills confirms the opportunity to apply robotics in the wider educational contexts. Moreover, starting from this observation, we have formulated the hypothesis that using educational robotics is fit for soft-skills training, as it exploits the mediation of new relationships that are established and kept alive in the children/adolescents group, by promoting everyone's participation in a context that is very different from everyday classroom activities, foresees interaction with tangible materials, and proposes challenging and always changing tasks. Moreover, it is necessary to verify if the peculiarities of robotics are crucial to impact on softskills; in other words, if soft-skills are promoted by the educational robotics side or by the laboratory side. The next step will be verifying this hypothesis in this emerging field.

\section{References}

Bacolod, M., Blum, B. S., Strange, W. C. (2009). Urban interactions: Soft skills versus specialization. Journal of Economic Geography, 9 (2), 227-262.

Benitti, F. B. V. (2012). Exploring the educational potential of robotics in schools: A systematic review. Computers \& Education, 58(3), 978-988.

Caudron, S. (1999). The hard case for soft skills. Workforce, 78 (7), 60-64.

Klassner, F., Anderson, S. D. (2003). Lego MindStorms: Not just for K-12 anymore. IEEE Robotics \& Automation Magazine, 10(2), 12-18.

Merdan, M., Lepuschitz, W., Koppensteiner, G., Balogh, R. (2016). Robotics in Education.

Miglino, O., Lund, H. H., \& Cardaci, M. (1999). Robotics as an educational tool. Journal of Interactive Learning Research, 10(1), 25.

Miglino, O., Rubinacci, F., Pagliarini, L., \& Lund, H. H. (2004). Using artificial life to teach evolutionary biology. Cognitive Processing, 5(2), 123-129.

Miglino, O., Di Ferdinando, A., Rega, A., \& Ponticorvo, M. (2007). Le nuove macchine per apprendere: simulazioni al computer, robot e videogiochi multi-utente. Alcuni prototipi. Sistemi Intelligenti, 18(1), 103-136. Miglino, O., Gigliotta, O., Ponticorvo, M., \& Nolfi, S. (2008). Breedbot: an evolutionary robotics application in digital content. The Electronic Library, 26(3), 363-373.

Owens, G., Granader, Y., Humphrey, A., Baron-Cohen, S. (2008). LEGO therapy and the social use of language programme: An evaluation of two social skills interventions for children with high functioning autism and Asperger syndrome. Journal of autism and developmental disorders, 38(10), 1944-1957.

Rubinacci, F., Ponticorvo, M., Gigliotta, O., \& Miglino, O. (2017). Breeding Robots to Learn How to Rule Complex Systems. In Robotics in Education (pp. 137-142). Springer, Cham.

Whittier, L. E., Robinson, M. (2007). Teaching evolution to non-English proficient students by using lego robotics. American Secondary Education, 19-28. 